\title{
Barriers to TQM Implementation within a Private Medical Services Organizations in Saudi Arabia
}

\author{
Abdulrahman Alsughayir ${ }^{1}$ \\ ${ }^{1}$ School of Economics \& Administrative Science, Al - Imam Muhammad ibn Saud Islamic University, Riyadh, \\ Kingdom of Saudi Arabia \\ Correspondence: Abdulrahman Alsughayir, Assistant Professor, Dean of Student Affairs, School of Economics \& \\ Administrative Science, Al - Imam Muhammad ibn Saud Islamic University, P.O. box 21525, Riyadh 11485, \\ Kingdom of Saudi Arabia. E-mail: aaalsughayir@yahoo.com
}

Received: February 23, 2014

Accepted: March 10, $2014 \quad$ Online Published: May 6, 2014

doi:10.5430/ijba.v5n3p117

URL: http://dx.doi.org/10.5430/ijba.v5n3p117

\begin{abstract}
This paper focuses on the barriers that private medical services organizations have faced while trying to implement Total Quality Management (TQM). The study employed a quantitative methodology involving 220 questionnaires that were validated and structured and consisted of 21 items identifying barriers faced by organizations during the implementation of TQM. Using convenience sampling techniques, we distributed the questionnaires to targeted employees of a four private medical services organization in Riyadh, Saudi Arabia. All statistical analysis was conducted in SPSS version 18 using descriptive data, reliability, and factor analysis to explore the barriers to the implementation of TQM. This analysis showed the most significant barriers to implementation were frequent employee turnover, resistance to change among employees, and a lack of understanding about TQM and a shortage of motivation among management. The results provide new impetus for findings from previous studies and offer human resource practitioners, quality managers, and professionals an opportunity to develop plans that addresses the challenges they face when implementing TQM, as well as intervention strategies with which to minimize the impact these challenges.
\end{abstract}

Keywords: TQM, implementation, barriers, Riyadh, Saudi Arabia

\section{Introduction}

Total Quality Management (TQM) has become one of the main strategies for improving business results and organizational performance in recent decades. Its ultimate aim is to achieve business excellence; although this concept can appear somewhat vague, it is generally associated with using high-quality organizational practices to gain a competitive edge (Naslund, 2008). Globalization and rapid technological change have presented Saudi organizations with opportunities to enhance their market share in existing markets, and also to move into new markets. The use of TQM and the adoption of the concept as an organizational strategy can help firms to utilize these opportunities.

TQM is a positive attempt by an organization to improve, through its structure, infrastructure, attitude, behavior, and methodology, the way it delivers to its end customers, all while emphasizing consistency, competitive enhancements, and improvements in quality (Zairi \& Youssef, 1995). In Japan, the "soft" factors of TQM are commonly emphasized, such as "an organisational culture dedicated to training, continuous improvement, and customer satisfaction" (Fotopoulos, 2009). This description matches Berry's (1991) definition of the TQM process as a holistic corporate focus on not only meeting but exceeding the expectations of customers, and adopting a new corporate culture and management system that helps reduce the costs that result from poor quality.

Many organizations have tried unsuccessfully to implement TQM, which often has a significant cost for their business. Critics have argued that TQM can sometimes require excessive use of time and other resources (Albarq, 2014). Others have claimed that the award frameworks (commonly used as the basis for implementing TQM) focus too much on processes and non-financial aspects of performance, which means they do not adequately define quality as an organizational goal (Ghobadian \& Gallear, 1996). There is also some confusion about TQM's core concepts and its critical success factors. Despite several attempts to identify these concepts and factors (Ahire et al., 1996), little consensus exists about precisely what it is that organizations must do in order to achieve business excellence through TQM. 
While TQM is not necessarily a new concept in Saudi Arabia, it is at the improvement stage, which means that managers must consider the appropriate application of TQM, particularly in small and medium-sized enterprises (SMEs). Studies to TQM implementation have focused more on large firms than on SMEs (Yusof \& Aspinwall, 2005). Many of those studies that have focused on SMEs have looked at the approaches that these firms have taken to TQM. Yusof and Aspinwall (2005) found that the TQM implementation frameworks did not fit the SME context. Kanji (1996) argued that "management failure to lead is the primary obstacle to successful TQM implementation." A number of case studies have found that poor management practices contributed to the failure of TQM initiatives. The most significant contributing factor was a management style that inhibits a learning culture and creates inter-departmental barriers (Sebastinelli \& Tamimi, 2003).

Similarly, Kotter (1995) found that the factors that hinder successful TQM implementation, especially in SMEs, are a lack of vision, poor communication, inadequate coordination with partners, and a lack of institutionalizing quality. Ngai and Cheng (1997) identified barriers related to culture, employees, managerial orientation and focus, infrastructure, and internal harmony and communication. According to Newall and Dale (1990), the major obstacles are obsolete culture and inadequate strategic planning. Although there are many studies about the barriers of TQM implementation in the literature, scholars such as (Fotopoulos, 2009; Naslund, 2008; Das et al., 2011; Khan, 2011; Sebastinelli \& Tamimi, 2003; Zairi \& Youssef, 1995; Hokoma, 2010) recommend that further attention and concern should be made for the investigation TQM implementation barriers and of critical success factor of TQM,

Therefore, the present study intends to investigate barriers to the implementation of TQM that service organizations in Saudi Arabia have experienced. We expect that the study will contribute to TQM research and identify barriers for successful implementation by way of a survey. The results of the present study may help health-care managers to deal with the barriers to implementing TQM in health-care organizations. Keeping the above in mind, this study aims to identify the barriers to successful TQM implementation in private Saudi Arabian medical services organizations.

\section{Methods and Materials}

The study was quantitative in nature and collected data via a self-administered questionnaire. The questionnaire included five-point Likert scales that ranged from "strongly disagree" to "strongly agree" and aimed to identify the critical barriers that Saudi medical service organizations faced in the implementation of TQM. We adopted questionnaire items from the literature (Tamimi \& Sebastianelli, 1998) and designed the questionnaire for self-completion; a total of 21 items identified barriers facing organizations in terms of TQM implementation. The text of the questionnaire was translated into Arabic, localized to the Saudi Arabian context, and then translated back into English in order to ensure the translation's equivalency and appropriateness. We validated the questionnaire by distributing it to selected academics in Saudi Arabia who specialize TQM. We made some amendments based on their feedback and revalidated the document. We then conducted a pilot test on a convenience sample of 10 percent $(n=22)$ of the target sample so that we could assess the Cronbach's coefficient alpha test efficiency (a tool for determining the reliability of the questionnaire questions). The result was 0.896 , which is above the acceptable cut-off value of 0.70 (Abbas et al., 2013). We excluded the pilot test data from the final analysis. We also measured the Kaiser-Meyer-Olkin (KMO) and Bartlett's sphericity test for each factor. We did not consider factor loading with values less than 0.50 for the analysis.

We used the results of the pilot test and the expert consultations to improve the content validity and clarity of wording in the questionnaire, and to enhance its overall user-friendliness. Two hundred and twenty copies of the questionnaire were distributed to targeted employees within four private Saudi medical services organizations, using a convenience sampling technique. We assured confidentiality and explained that we would analyze and report the research data only in aggregate form. We tracked the responses to the initial questionnaire; employees who had not responded as of the deadline were sent a polite reminder letter that emphasized the importance of their contribution, along with another copy of the questionnaire. We then allowed two weeks more for those employees to return their questionnaires before calculating the final response rate. We analyzed the collected data using the SPSS software program version 18.0.

\section{Results}

A total of 198 of the 220 employees returned questionnaires. Of these 198, we rejected 11 responses because they had not completed the questionnaire. We then screened the response data and classified a further four responses as unusable or outliers. These 15 responses were excluded from the study, leaving us with 183 useable responses, (83.2 percent).

In this study, the sample characteristics include five major items: (1) gender, (2) marital status, (3) age, (4) education level, (5) and monthly income. Table 1 presents the results that we obtained for these items. 
Table 1. Results of demographic data $(\mathrm{n}=183)$

\begin{tabular}{llcc}
\hline Variables & Valid & Frequency & Percentage (\%) \\
\hline \multirow{2}{*}{ Gender } & Male & 122 & 66.6 \\
& Female & 61 & 33.4 \\
\hline \multirow{4}{*}{ Education level } & High school & 58 & 31.7 \\
& Bachelor degree & 114 & 62.2 \\
& Master's degree & 11 & 6.1 \\
& Doctoral degree & 0 & 0 \\
\hline \multirow{3}{*}{ Material status } & Single & 82 & 44.8 \\
& Married & 94 & 51.4 \\
& Other & 7 & 3.8 \\
\hline \multirow{4}{*}{ Age } & $18-25$ & 19 & 10.4 \\
& 26-35 & 82 & 44.8 \\
& $36-45$ & 68 & 37.2 \\
\multirow{5}{*}{ Monthly income } & 46 and above & 14 & 7.6 \\
& Less than 5000 SAR & 9 & 4.9 \\
& 5001-10,000 SAR & 81 & 44.2 \\
& $10,001-15,000$ SAR & 71 & 38.7 \\
\hline
\end{tabular}

Once we established that there was no missing data or outliers in the final dataset, we used the SPSS 18.0 computer software to calculate the descriptive statistics for all of the items (see Table 2). Table 2 shows the standard deviation and mean of each barrier. The mean values of the responses ranged from 1.74 to 3.03 ; a higher mean represents greater importance of the barrier. These results show that the most significant barrier to TQM is employees' resistance to change, which has a mean value of $3.03, \mathrm{SD}=0.91$. This was followed by "Management decisions are always short-term-oriented" $(\mathrm{M}=2.93, \mathrm{SD}=0.88)$ and "Quality action plans are often vague" $(\mathrm{M}=2.75, \mathrm{SD}=0.97)$ and "frequent turnover of employees" ( $\mathrm{M}=2.64, \mathrm{SD}=0.81)$.

The high KMO measure of the factor analyses showed that they met the appropriate statistical assumptions. The KMO value $(0.891)$ and Bartlett's test of sphericity $(0.000)$ were within the high range. The factor analysis extracted six factors, which accounted for 71.3 percent of the variance. We used a reliability test to measure the consistency of the individuals' responses. We used Cronbach's alpha to examine the survey's internal consistency, and based the research variables on sample estimation. The Cronbach's alpha for all factors was within the acceptable range recommended by Nunnally (1978).

Table 2. The results of descriptive analysis of each barrier $(\mathrm{n}=183)$

\begin{tabular}{lllll}
\hline Item & Barriers to implementing TQM from employees' perspective & Rank & Mean & SD \\
\hline 1 & Resistance to change & 1 & 3.03 & 0.91 \\
18 & Frequent turnover of employees & 2 & 2.93 & 0.88 \\
10 & Lack of motivation & 3 & 2.75 & 0.97 \\
15 & Lack of understanding of TQM concepts & 4 & 2.64 & 0.81 \\
5 & Belief that quality is expensive & 5 & 2.60 & 0.89 \\
16 & Quality action plans are often vague & 6 & 2.56 & 0.82 \\
2 & Lack of a sense of unity and loyalty & 7 & 2.53 & 0.86 \\
19 & Quality is not measured effectively & 8 & 2.44 & 0.88 \\
8 & Management decisions are short-term-oriented. & 9 & 2.37 & 1.11 \\
11 & The strategic plan is not customer-driven & 10 & 2.33 & 0.98 \\
21 & The high costs of implementing TQM outweigh the benefits & 11 & 2.25 & 1.01 \\
7 & Lack of commitment from workers & 12 & 2.17 & 0.94 \\
14 & Top management is not committed to quality & 13 & 2.13 & 0.87 \\
13 & Quality is treated as a separate initiative & 14 & 2.05 & 0.93 \\
12 & Management's compensation is not linked to achieving quality goals & 15 & 2.01 & 0.95 \\
3 & Employees are not empowered to implement quality improvement & 16 & 1.97 & 1.13 \\
4 & Time constraints prohibit effective TQM implementation & 17 & 1.94 & 0.92 \\
6 & Lack of knowledge and skills & 18 & 1.86 & 0.79 \\
9 & There is no joint planning with suppliers & 19 & 1.81 & 0.90 \\
17 & The best practices and/or products of other companies are not benchmarked & 20 & 1.78 & 0.78 \\
20 & Quality is not defined by the customer & 21 & 1.74 & 0.63 \\
\hline
\end{tabular}

$\mathrm{M}=$ Mean. A five-point Likert scale was used, where $1=$ not at all true and $5=$ completely true. $\mathrm{SD}=\mathrm{Standard}$ Deviation. 


\section{Discussion}

According to our analysis, most of the respondents felt that these barriers items are significant for effective TQM implementation. Other studies support this result. For example, according to Khan (2011), the major barrier to TQM implementation was resistance to change among employees. Bhat and Rajashekhar (2009) expressed similar thoughts based on a similar study in India.

However, Salaheldin's (2009) study in an Egyptian context concluded that the commitment of top management in the promotion of TQM implementation is significant. Das et al.'s (2011) findings were similar. Chapman and Al-Khawaldeh (2002) concluded that customer focus is an important part of fixing and resolving customer's problems and complaints in those companies that applied TQM.

The most significant barrier according to the present study was employees' resistance to change. Success in TQM implementation requires an organization to consider cultural change as an essential factor. TQM spurs a complete change in the feelings, attitudes, behavior, and job-related practices of the organization's employees.

An organization's management and employees act as a team and provide the synergy required to achieve the organizational goals. Processes are redesigned so that they benefit the employees. Such a cultural transformation requires changes to be made in every area of organizational work. The employees who responded to our questionnaire have expressed fear about such a transformation and have experienced physical and psychological fear. Many of them regard the transformation as a setback to their attitude and practices, which causes them to resist the change. Evans and Lindsay (2002) argued that the success of such a transformation requires the development of people skills, the alignment of the organizational structure and the system, and development of management's interpersonal style.

According to our findings, the second-most important barrier to TQM is frequent employee turnover. High employee turnover rates generally indicate that companies are selecting the wrong employees, not providing a motivating work environment, or losing the best employees to other organizations that offer better conditions. A significantly negative effect of turnover is decreased performance quality (Albarq, 2013). Jun et al.'s (2004) study showed that high employee turnover was a major barrier to TQM implementation in Mexican organizations.

Another potential barrier to TQM implementation is a lack of motivation found by the present study. Understanding and commitment are required in order to achieve motivation (Bateman \& Snell, 2002), so employees who do not have a clear idea of what TQM is may lack the motivation to embrace the continuous improvement philosophy. Because organizational success is tied to employee motivation, organizations should develop their policies and organizational structures in a way that gives their employees space to work well, and should appreciate employees who fulfil and exceed their tasks (Das et al., 2011).

Furthermore, the present study found lack of understanding about the TQM concept was another major factor that affects TQM implementation. Powell (1995) found that employees who were involved in quality-related issues increased their understanding of quality problems and resolved these issues at their own level. TQM requires managers to provide an inspirational vision, make strategic directions that everyone understands, and instil values that help to guide subordinates. The success of TQM relies on supervisors who are committed to leading their employees. Supervisors need to understand and believe in TQM, and then demonstrate this commitment in their daily TQM practice.

The present study can help corporate decision makers, quality experts, business leaders, human resource practitioners, and academics with the opportunity to understand the impediments to sustainable TQM success. The study has identified some of the main barriers to TQM implementation, the most significant of which are employees' resistance to change, frequent employee turnover, and a lack of motivation. There is a direct correlation between these factors and organizational planning and leadership support for successful TQM initiatives.

A limitation of the study is that it investigated only four service organizations. The convenience sampling technique used in the study, as well as the limited number of respondents will probably affect the generalizability of the results. Future research should be conducted with larger organizations, both in the product and service sectors.

\section{Conclusion}

This study has empirically examined the barriers that a medical service organizations faces when implementing TQM in a developing economy. The implementation of TQM and the realization of the desired objectives take time. Managers need to be aware of and understand the effects that these obstacles have on their desired TQM outcomes. Success is highly dependent on managers being aware of these barriers and responding proactively in order to prevent these obstacles arising at an earlier stage. 


\section{References}

Abbas, A., Suleiman, A., \& Almualla, A. (2013). Using structural equation modeling for beginner. Amman: Ithraa, Inc.

Ahire, S. L., Golhar, D. Y., \& Waller, M. A. (1996). Development and validation of TQM implementation constructs. Decision Sciences, 27(1), 23-56. http://dx.doi.org/10.1177/0266242608098348

Albarq, A. (2013). Applying a SERVQUAL Model to Measure the Impact of Service Quality on Customer Loyalty among Local Saudi Banks in Riyadh. American Journal of Industrial and Business Management, 3(8), $700-707$. http://dx.doi.org/10.4236/ajibm.2013.38079

Albarq, A. (2014). Industrial Purchase among Saudi Managers: Does Country of Origin Matter?. International Journal of Marketing Studies, 6(1), 116-126. http://dx.doi.org/10.5539/ijms.v6n1p116

Berry, T.H. (1991). Managing the Total Quality Transformation. McGraw-Hill, New York, NY.

Bhat, K.S., \& Rajashekhar, J. (2009). An empirical study of barriers to TQM implementation in Indian industries. The TQM Magazine, 21(3), 261-272.

Chapman, R., \& Al-Khawaldeh, K. (2002). TQM and labour productivity in Jordanian industrial companies. The TQM Magazine, 14(4), 248-262. http://dx.doi.org/10.1108/09544780210429861

Das, A., Kumar, V., \& Kumar, U. (2011). The role of leadership competencies for implementing TQM: An empirical study in Thai manufacturing industry. International Journal of Quality \& Reliability Management, 28(2), 195-219.

Evans, J.R., \& Lindsay, W.M. (2002). The Management and Control of Quality (5 ed.). South-Western, USA.

Fotopoulos, C.V. (2009). The Impact of "Soft" and "Hard" TQM Elements on Quality Management Results. International Journal of Quality and Reliability Management, 26(2), 150-163.

Ghobadian, A., \& Gallear, D.N. (1996). Total quality management in SMEs. OMEGA, 24(2), 83-106.

Hokoma, R. A., Khan, M. K., \& Hussain, K. (2010). The present status of quality and manufacturing management techniques and philosophies within the Libyan iron and steel industry. The TQM Journal, 22(2), $209-221$.

Jun, M., S. Cai, \& Peterson, R.T. (2004). Obstacles to TQM Implementation in Mexico's Maquiladora Industry. Total Quality Management, 15(1), 59-72

Kanji, G.K. (1990). Total quality management: the second industrial revolution. Total Quality Management, 1, 3-12.

Kanji, G.K. (1996).Total quality management: the second industrial revolution. Total Quality Management, 1, 3-12.

Khan, M. (2011). An Empirical Study of Barriers in Implementing Total Quality Management in Service Organizations in Pakistan. Asian Journal of Business Management Studies, 2(4), 155-161.

Kotter, J.P. (1995, March-April). Leading change: Why transformation efforts fail. Harvard Business Review, 59-66.

Lee, K.S. (2005). Ergonomics in Total Quality Management: How can we Sell Ergonomics to Management? Ergonomics, 48(5), 547-558. http://dx.doi.org/10.1080/00140130400029282

Naslund, D. (2008). Lean, six sigma and lean six sigma: fads or real process improvement methods. Business Process Management, 14, 269-287. http://dx.doi.org/10.1108/14637150810876634

Newall, E., \& Dale, B. (1990). The introduction and development of a quality improvement process: A study. International Journal of Production Research, 29(9), 351-359.

Ngai, E.W., \& Cheng, T.C. (1997). Identifying potential barriers to total quality management using principal component analysis and correspondence analysis. International Journal of Quality and Reliability Management, 14(4), 391-408. http://dx.doi.org/10.1108/02656719710170657

Nunnally, J. (1978). Psychometric Theory. New York: McGraw-Hill.

Salaheldin, S. I. (2009). Critical success factors for TQM implementation and their impact on performance of SMEs. International Journal of Productivity and Performance Management, 58(3), 215-237. http://dx.doi.org/10.1108/17410400910938832

Sebastianelli, R., \& Tamimi, N. (2003). Understanding the obstacles to TQM Success. Quality Management Journal, $10(3), 45-55$.

Yusof, S.M., \& Aspinwall, E.M. (2005). A conceptual framework for TQM implementation for SMEs. The TQM Magazine, 12(1), 31-36.

Zairi, M. (2002). Beyond TQM implementation: The new paradigm of TQM sustainability. Total Quality Management, 13, 1161-1172. 